\title{
Tandem Mass Spectrometric Study of Ciprofloxacin-Poly(ethylene glycol) Conjugate in the Presence of Alkali Metal Ions
}

\author{
Sándor Kéki ${ }^{1}$, Lajos Nagy ${ }^{1}$, Ákos Kuki ${ }^{1}$, Gábor Pintér ${ }^{2}$, Pál Herczegh ${ }^{2}$, Miklós Zsuga $^{{ }^{*}}$ \\ ${ }^{1}$ Department of Applied Chemistry, University of Debrecen, H-4012 Debrecen, Hungary \\ ${ }^{2}$ Department of Pharmaceutical Chemistry, University of Debrecen, H-4012 Debrecen,
}

\section{Hungary}

\begin{abstract}
The fragmentation and fragmentation behaviors of singly, doubly, and triply charged adducts of ciprofloxacin-poly(ethylene glycol) conjugate $\left(\mathrm{P} \_\mathrm{Cf}\right)$ with alkali metal ions, including $\mathrm{Li}^{+}$, $\mathrm{Na}^{+}$and $\mathrm{K}^{+}$ions, generated by electrospray (ESI) were studied as a function of collision energy. The product ion spectra of adducts with charge states $+1,+2$, and +3 are dominated by product ions arising from the loss-neutral moiety (ciprofloxacin) and $\mathrm{CO}_{2}$, and ions formed by dissociation of the precursor ion $\left(\left[\mathrm{P} \_\mathrm{Cf}+\mathrm{xM}\right]^{\mathrm{x}+}\right)$ into product ions $[\mathrm{P}+(\mathrm{x}-1) \mathrm{M}]^{(\mathrm{x}-1)+}$ and $[\mathrm{Cf}+\mathrm{M}]^{+}$(where $\mathrm{P} \_\mathrm{Cf}, \mathrm{P}$ and $\mathrm{Cf}$ represent the ciprofloxacin-poly(ethylene glycol) conjugate, the poly(ethylene glycol) backbone without the endgroups, and the ciprofloxacin moiety, respectively; $\mathrm{M}$ is the alkali metal ion and $\mathrm{x}$ is the charge). It was found that the metal ions do not significantly alter the fragmentation pattern of ciprofloxacin-poly(ethylene glycol) conjugate. It is also interesting that the run and the shape of the survival yield curves for the singly and doubly charged adduct ions are independent of the cation. However, in the case of triply charged adducts, survival yield curves follow each other in the order $\mathrm{K}^{+}, \mathrm{Na}^{+}$, and $\mathrm{Li}^{+}$. Based on the experimental results, a fragmentation mechanism for the singly and multiply charged adducts of $\mathrm{P}_{-} \mathrm{Cf}$ with alkali metal ions is given. In addition, a tentative description of the signal intensity variations of the product ions with the lab frame collision energy is also reported.
\end{abstract}

Keywords: ciprofloxacin-poly(ethylene glycol) conjugate, fragmentation, energy-variable collision-induced dissociation, cation attachment 


\section{Introduction}

Ciprofloxacin [1] is the most prominent member of a group called the fluoroquinolones. Ciprofloxacin is frequently used as a wide-spectrum antibiotic to treat and prevent infections caused by bacteria both in human and animal bodies. Additionally, ciprofloxacin has also been approved as a very effective medicine for countering the inhaled form of anthrax [2]. Due to the potential risk of establishing resistance caused by antibiotic residues in foods of animal origin, the European Union Committee has set legislation for the level of different antibiotics residing in foodstuffs [3]. Partly owing to these rigorous regulations, several methods for the qualitative and quantitative determination of antibiotics has been applied for these purposes; however, the most selective of these methods is liquid chromatography (LC) combined with mass spectrometry (MS) [4-10]. Therefore, the fragmentation properties of various antibiotics, including that of ciprofloxacin under electrospray conditions, have been studied $[11,12]$.

During our research on the modification of several antibiotics, we aimed at the pegilation of ciprofloxacin, i.e., the synthesis of ciprofloxacin-poly(ethylene glycol) conjugate (P_Cf). Mass spectrometry analysis of $\mathrm{P}_{-} \mathrm{Cf}$ conjugate showed that under electrospray conditions, it readily forms singly and multiply charged adducts with alkali metal ions due to the presence of the poly(ethylene glycol) backbone. From a mass spectrometry point of view, it is important to gather information as to how the cation and the charge state of adducts, as well as the collision energy, affect the fragmentation behaviors of such conjugates. In this article, we report a detailed energy-variable collision-induced dissociation study of singly and multiply charged adducts of $\mathrm{P}_{-} \mathrm{Cf}$ conjugate with alkali metal ions $\left(\mathrm{K}^{+}, \mathrm{Na}^{+}, \mathrm{Li}^{+}\right)$

\section{Experimental}

\section{Chemicals.}

All chemicals used were received from Aldrich (Seelze, Germany). Sample solutions were prepared in methanol at a concentration of $1 \mathrm{mM}$ ciprofloxacin-poly(ethylene glycol) conjugate (P_Cf) and $1 \mathrm{mM}$ alkali metal chlorides ( $\mathrm{LiCl}, \mathrm{NaCl}$ and $\mathrm{KCl})$.

\section{Synthesis of the ciprofloxacin-poly(ethylene glycol) conjugate ( $\left.P_{-} C f\right)$}

Synthesis of the ciprofloxacin-poly(ethylene glycol) conjugate ( $\left.\mathrm{P}_{-} \mathrm{Cf}\right)$ began from poly(ethylene glycol) with a number average molecular weight of $1000 \mathrm{~g} / \mathrm{mol}$ possessing $-\mathrm{OCH}_{3}$ and $-\mathrm{OH}$ endgroups. The $-\mathrm{OH}$ termini were converted into $-\mathrm{NH}_{2}$ termini, followed by 
the latter's conversion to isothiocyanate and subsequent reaction with ciprofloxacin to give ciprofloxacin-poly(ethylene glycol) conjugate. P_Cf was characterized by using ${ }^{1} \mathrm{H}-\mathrm{NMR}$, ${ }^{13} \mathrm{C}-\mathrm{NMR}$, and IR-spectroscopy. The details of the synthesis will be reported in a separate paper. The chemical structure of $\mathrm{P}_{-} \mathrm{Cf}$ is shown in Scheme 1.

Scheme 1.

\section{Instrumentation.}

Electrospray Quadrupole Time-of-Flight MS/MS (ESI-Qq-TOF).

MS/MS measurements were performed with a MicroTOF-Q type Qq-TOF MS instrument equipped with an ESI source from Bruker (Bruker Daltoniks, Bremen, Germany). The sample solutions were introduced directly into the ESI source with a syringe pump (Cole-Parmer Ins. Co., Vernon Hills, IL, USA) at a flow rate of $2 \mu \mathrm{L} / \mathrm{min}$. The temperature of the drying gas $\left(\mathrm{N}_{2}\right)$ was maintained at $100^{\circ} \mathrm{C}$. The needle voltage was $4 \mathrm{kV}$. For MS/MS experiments, nitrogen gas was used as the collision gas and the collision energies were varied in the range of $10-100 \mathrm{eV}$ (in the laboratory frame). The pressure in the collision cell was determined to be $8 \times 10^{-3}$ mbar. The precursor ions for MS/MS were selected with an isolation width of $5 \mathrm{Th}$. All the MS and MS/MS spectra were accumulated and recorded by a digitizer at a sampling rate of $2 \mathrm{GHz}$. The mass spectra were calibrated externally using the exact masses of clusters $\left[(\mathrm{NaTFA})_{\mathrm{n}}+\mathrm{Na}\right]^{+} \quad(\mathrm{n}=1-3)$ generated from the electrosprayed solution of sodium trifluoroacetate (NaTFA). The accuracy of mass determination was within $\pm 8 \mathrm{ppm}$. The mass spectra recorded were evaluated by the DataAnalysis 3.1 software from Bruker.

\section{Results and Discussion}

ESI-TOF MS of ciprofloxacin-poly(ethylene glycol) conjugate

The electrospray mass spectra of ciprofloxacin-poly(ethylene glycol) conjugate $\left(\mathrm{P} \_\mathrm{Cf}\right)$ in the presence of alkali metal ions $\left(\mathrm{Li}^{+}, \mathrm{Na}^{+}, \mathrm{K}^{+}\right)$revealed the presence of adducts with alkali metal ions of charge states ranging from +1 to +4 . Additionally, besides these adduct ions (most probably due to the basic character of $\mathrm{N}$ atoms in the ciprofloxacin endgroup), protonated molecules of $\mathrm{P}_{-} \mathrm{Cf}\left(\left[\mathrm{P} \_\mathrm{Cf}+\mathrm{H}\right]^{+}\right)$and mixed adducts e.g., $\left[\mathrm{P} \_\mathrm{Cf}+\mathrm{H}+\mathrm{Na}\right]^{2+}$ with relative low intensity also occurred in the ESI-MS spectra. As a representative example, the ESI-MS spectrum of $\mathrm{P}_{-} \mathrm{Cf}$ in the presence of sodium ions is presented in Fig. 1. 
Fig. 1.

As is evident in Fig. 1, under electrospray conditions, the formation of adducts $\left[\mathrm{P} \_\mathrm{Cf}+\mathrm{xNa}\right]^{\mathrm{x}+}$ with $\mathrm{x}=1$ to 4 are preferred with the presence of some low-intensity mixed adduct ions, e.g., $\left[\mathrm{P} \_\mathrm{Cf}+\mathrm{H}+\mathrm{Na}\right]^{2+}$. Similar mass spectra were recorded for the electrospayed solution of $\mathrm{P}_{-} \mathrm{Cf}$ containing $\mathrm{Li}^{+}$and $\mathrm{K}^{+}$ions. However, it was found that the degree of polymerization (DP, i.e., number of repeat units) belonging to the most probable peak varied with charge state and the cation, as depicted in Fig. 2.

Fig. 2.

As shown in Fig. 2, the DP of the most probable peak increases with the charge state. This effect is presumably due to the fact that longer chains can accommodate more ions owing to coulombic repulsion, thereby shifting the most probable peak position to a higher DP value. On the other hand, the cation also affects the DP of the most probable peak. It is also evident from Fig. 2 that the larger the cation size, the higher the DP value for the most probable peak for each charge state, as judged from the results obtained for $\mathrm{Li}^{+}$and $\mathrm{Na}^{+}$. (The ionic radii for $\mathrm{Li}^{+}$and $\mathrm{Na}^{+}$are 80 and $120 \mathrm{pm}$, respectively.) However, the result for $\mathrm{K}^{+}$does not fit in the above trend, since the ionic radii of $\mathrm{K}^{+}(180 \mathrm{pm})$ are higher than those of $\mathrm{Li}^{+}$and $\mathrm{Na}^{+}$, and the observed DP value lies between the two. The reason for this may be a more specific interaction of the $\mathrm{K}^{+}$ions not only with the oxygen atoms of ethylene oxide repeat units, but also with those of the endgroups (ciprofloxacin moieties). The carboxyl group in the ciprofloxacin moiety may enable the formation of a salt bridge with the alkali metal ions. However, the formation of such structure is most probable with potassium ion and a salt bridge with this ion may decrease the size of PEG chain required to ligate most favorably two $\mathrm{K}^{+}$ions as suggested by one of our reviewers. The formation of such salt bridge may be the reason for the different trend observed for $\mathrm{K}^{+}$ion.

\section{ESI-TOF MS/MS of ciprofloxacin-poly(ethylene glycol) conjugate}

To study the fragmentation properties of $\mathrm{P}_{-} \mathrm{Cf}$ cationized with alkali metal ions, some oligomer peaks were selected for MS/MS experiments. The primary goal of the present study was to investigate the effects of the cations on the fragmentation properties of $\mathrm{P} \_\mathrm{Cf}$ as a function of the collision energy. The energy transferred to the precursor ion in collisions with 
the background gas molecules depends on the mass and the degree of freedom of the precursor ion. Therefore, oligomer peaks with approximately the same number of repeat units were selected for adducts of each cation in the MS/MS experiments, allowing direct comparison of the effect of cations on the fragmentation behavior without any further corrections. (In this case, the molecular weight and the degrees of freedom (DOF) of the precursor ion were practically constant, otherwise the obtained data would need to be corrected with the mass and DOF values.) For this reason, $\mathrm{P}_{-} \mathrm{Cf}$ with repeat unit numbers of 21-22, 24-25, and 27-28 were selected for MS/MS experiments in the case of singly, doubly, and triply charged adducts, respectively. A representative first-generation product ion spectrum (ESI-QqTOF MS/MS) for the precursor ion $\left[\mathrm{P} \_\mathrm{Cf}+2 \mathrm{Na}\right]^{2+}$ is shown in Fig. 3.

Fig. 3.

As can be seen in Fig 3, the precursor ion $\left[\mathrm{P} \_\mathrm{Cf}+2 \mathrm{Na}\right]^{2+}$ dissociates to give product ion $[\mathrm{P}+2 \mathrm{Na}]^{2+}$ by the loss of a neutral ciprofloxacin moiety. In parallel, elimination of a $\mathrm{CO}_{2}$ molecule from the precursor also takes place, yielding product ion $\left[\mathrm{P} \_\mathrm{Cf}-\mathrm{CO} 2+2 \mathrm{Na}\right]^{2+}$. The elimination of $\mathrm{CO}_{2}$ from $\left[\mathrm{P} \_\mathrm{Cf}+2 \mathrm{Na}\right]^{2+}$ indicate that a salt bridge with $\mathrm{Na}^{+}$ion was also formed to some extent as suggested by one of our reviewers. The presence of $[\mathrm{Cf}+\mathrm{Na}]^{+}$ion indicates that the charge is retained on the ciprofloxacin moiety. A singly charged product ion such as $[\mathrm{P}+\mathrm{Na}]^{+}$was also formed. The breakdown curves for the precursor ion $\left[\mathrm{P} \_\mathrm{Cf}+2 \mathrm{Na}\right]^{2+}$ are presented in Fig. 4.

Fig. 4.

As seen in Fig. 4, the intensity of $[\mathrm{P}+2 \mathrm{Na}]^{2+}$ product ion increases rapidly in the range from $30 \mathrm{eV}$ to $50 \mathrm{eV}$. The parallel occurrence of the product ion $[\mathrm{P}+\mathrm{Na}]^{+}$with that of $[\mathrm{Cf}+\mathrm{Na}]^{+}$ suggests that the former was produced by the process $\left.\left[\mathrm{P} \_\mathrm{Cf}+2 \mathrm{Na}\right]^{2+}\right][\mathrm{P}+\mathrm{Na}]^{+}+[\mathrm{Cf}+\mathrm{Na}]^{+}$ rather than by $[\mathrm{P}+2 \mathrm{Na}]^{2+}[\mathrm{P}+\mathrm{Na}]^{+}+\mathrm{Na}^{+}$. At higher collision energies, especially above 60 $\mathrm{eV}$, the intensity of $[\mathrm{P}+2 \mathrm{Na}]^{2+}$ product ion decreases, most probably due to dissociation into $[\mathrm{P}+\mathrm{Na}]^{+}$and $\mathrm{Na}^{+}$. Depletion of all other singly charged product ions with the increasing collision energy is a consequence of detachment of sodium ion from the corresponding ion to yield neutral molecules and bare sodium ions. Breakdown curves for the triply charged $\mathrm{P}_{-} \mathrm{Cf}$ shows characteristics (Fig. 5) similar to those of the doubly charged ions, with some exceptions. 
Fig. 5.

Product ions formed by loss of a $\mathrm{CO}_{2}$ molecule from the precursor appeared only with very low intensity. In contrast, the major product ion $[\mathrm{P}+2 \mathrm{Na}]^{2+}$ was probably formed by the dissociation of $\left[\mathrm{P} \_\mathrm{Cf}+3 \mathrm{Na}\right]^{3+}$ into ions $[\mathrm{P}+2 \mathrm{Na}]^{2+}$ and $[\mathrm{Cf}+\mathrm{Na}]^{+}$.

The collision-induced dissociation of singly charged sodiated adducts of $\mathrm{P}_{-} \mathrm{Cf}$ give only two product ions, $\left[\mathrm{P} \_\mathrm{Cf}-\mathrm{CO} 2+\mathrm{Na}\right]^{+}$and $[\mathrm{P}+\mathrm{Na}]^{+}$. It is interesting to note that formation of the product ion $[\mathrm{Cf}+\mathrm{Na}]^{+}$was not observed at all. Breakdown curves for the singly charged sodiated adduct (not shown) revealed that the intensity of $[\mathrm{P}+\mathrm{Na}]^{+}$increased with the collision energy up to $80 \mathrm{eV}$, but in the range of $80-100 \mathrm{eV}$ (in the laboratory frame) the intensity of $[\mathrm{P}+\mathrm{Na}]^{+}$remained practically constant. This observation indicates that the adduct ion $[\mathrm{P}+\mathrm{Na}]^{+}$ is stable enough to survive collisions of such high energy. Thus, the conclusions drawn for the singly, doubly, and triple charged sodiated adducts of $\mathrm{P}_{-} \mathrm{Cf}$ are shown to also hold for the corresponding adducts of $\mathrm{P}_{-} \mathrm{Cf}$ with $\mathrm{Li}^{+}$and $\mathrm{K}^{+}$ions.

The survival yield $(\phi)$ was calculated using Eqn. 1, and the plots of $\phi$ as a function of the collision energy for each charge state and cation adduct are shown in Fig. 6.

$$
\phi=I_{\text {precursor }} /\left(I_{\text {precursor }}+\Sigma I_{i}\right)
$$

where $I_{\text {precursor }}$ is the intensity of the precursor ion and $\Sigma I_{i}$ is the sum of the intensities of all product ions appearing in the spectrum.

Fig. 6.

As evident in Fig. 6, the run and the shape of the survival yield curves for the singly and doubly charged adduct ions are independent of the cation. However, in the case of triply charged adducts, survival yield curves follow each other in the order $\mathrm{K}^{+}, \mathrm{Na}^{+}$, and $\mathrm{Li}^{+}$, indicating that potassiated adducts dissociate more easily than lithiated adducts do. These observations may indicate that the effect of charge repulsion between the cations on the dissociation of adducts becomes more pronounced for triply charged adduct ions. 
The main fragmentation schemes proposed for the singly and multiply charged adducts of P_Cf with alkali metal ions are summarized in Scheme 2.

\section{Scheme 2.}

According to Scheme 2, the dissociation of the precursor ion $\left[\mathrm{P} \_\mathrm{Cf}+\mathrm{xM}\right]^{\mathrm{x}+}$ takes place simultaneously via processes denoted by $\mathbf{a}, \mathbf{b}$, and $\mathbf{c}$. In process $\mathbf{a}$, the loss of an endgroup is operational, yielding product ions $[\mathrm{P}+\mathrm{xM}]^{\mathrm{x}+}$ and a neutral fragment $\mathrm{Cf}$. Further decomposition of $[\mathrm{P}+\mathrm{xM}]^{\mathrm{x}+}$ can also take place by detachment of the $\mathrm{M}^{+}$ion to give ion $[\mathrm{P}+(\mathrm{x}-1) \mathrm{M}]^{(\mathrm{x}-1)+}$ as indicated (process d). Process $\mathbf{b}$ yields product ions $[\mathrm{P}+(\mathrm{x}-1) \mathrm{M}]^{(\mathrm{x}-1)+}$ and $[\mathrm{Cf}$ $+\mathrm{M}]^{+}$. Note that the latter process occurs in the case of doubly and triply charged adducts, when $x=2$ and 3. A similar process does not take place for the singly charged adduct, as no $[\mathrm{Cf}+\mathrm{M}]^{+}$ions in the product ion spectra of $\left[\mathrm{P} \_\mathrm{Cf}+\mathrm{M}\right]^{+}$could be detected. Parallel to processes $\mathbf{a}$ and $\mathbf{b}$, elimination of a $\mathrm{CO}_{2}$ molecule from the precursor ion also operates (process $\mathbf{c}$ ), giving product ion $\left[\mathrm{P} \_\mathrm{Cf}-\mathrm{CO} 2+\mathrm{xM}\right]^{\mathrm{x}}$ which may undergo further decomposition to yield ions $[\mathrm{P}+(\mathrm{x}-1) \mathrm{M}]^{(\mathrm{x}-1)+}$ and $[\mathrm{Cf}-\mathrm{CO} 2+\mathrm{M}]^{+}$(process e). It should be emphasized, however, that ions $[\mathrm{P}+(\mathrm{x}-1) \mathrm{M}]^{(\mathrm{x}-1)+}$ and $[\mathrm{Cf}-\mathrm{CO} 2+\mathrm{M}]^{+}$occur only with very low intensities as compared to those of the other product ions. On the other hand, formation of product ion [P_Cf$\mathrm{CO} 2+\mathrm{xM}]^{\mathrm{x}+}$ in the case of triply charged adducts $(\mathrm{x}=3)$ can be detected only with very low intensity. Simple detachment of $\mathrm{M}^{+}$from the precursor ion $\left[\mathrm{P} \_\mathrm{Cf}+\mathrm{xM}\right]^{\mathrm{x}+}$ to give ion $\left[\mathrm{P} \_\mathrm{Cf}+\right.$ $(\mathrm{x}-1) \mathrm{M}]^{(\mathrm{x}-1)+}$ occurred at a detectable level only in the case of $\mathrm{x}=3$ (see Fig. 5); therefore, this process was not considered in Scheme 2.

\section{Kinetic consideration of product ion formation and depletion}

In general, in the case of parallel, consecutive reactions when the initial reactant decomposes by several parallel first-order reactions, each with rate constant of $k_{i}$, and the particular intermediate denoted by $P_{1}$ further decomposes with rate constant $k_{l}$ ' in a first-order reaction, then the concentration of $P_{l}\left(C_{B}\right)$ as a function of the reaction time $(\tau)$ can be given by

$$
c_{P_{1}}=\frac{k_{1}^{\prime} c_{A, o}}{k_{1}^{\prime}-\Sigma k_{i}}\left[\exp \left(-\Sigma k_{i} \tau\right)-\exp \left(-k_{1}^{\prime} \tau\right)\right]
$$


where $C_{A, o}$ is the initial concentration, and $\Sigma k_{i}$ is the sum of the rate constants of parallel reactions.

In tandem mass spectrometry experiments, the "reaction time" is practically constant while the internal energy gained during collisions is varied. As a first approximation, the dependence of the rate constant $(k)$ on the effective temperature $\left(T_{\text {eff }}\right)$ is assumed to obey the Arrhenius equation as:

$$
k=A \exp \left(-\frac{E_{a}}{R T_{e f f}}\right)
$$

$T_{\text {eff }}$ is not a real temperature, since the system is not in a thermal equilibrium; however, the value of $T_{\text {eff }}$ can be approximated by Eqn. 4 ,

$$
T_{\text {eff }}=\frac{E_{\mathrm{int}, o}+E_{\mathrm{int}}}{v R}
$$

where $v$ and $R$ are the number of degrees of freedom and the gas constant, respectively, and $E_{\text {int,o }}$ and $E_{\text {int }}$ represent the initial internal energy of the precursor ion and the internal energy acquired during collisions, respectively.

The internal energy gained during collision is proportional to the laboratory frame collisional energy $\left(E_{c}\right)$, as shown in Eqn. 5.

$$
E_{\text {int }}=\alpha E_{c}
$$

where $\alpha$ is the proportionality constant, which depends on several factors such as the crosssections, the molecular mass, and the efficiency of energy transfer from the background gas molecules $[13,14]$.

Substituting Eqn. 5 into Eqn. 4 then into Eqn. 3, and assuming that $E_{\text {int,o }}<<E_{\text {int, }}$ the dependence of an unimolecular rate constant on $E_{c}$ can be given by Eqn. 6 .

$$
k=A \exp \left(-b / E_{c}\right)
$$

where $b=E_{a^{v}} / \alpha$. 
Assuming linear relationships between the signal intensities and the gas-phase concentrations of the corresponding ions,

$$
I_{P_{1}}=\beta c_{P_{1}}
$$

where $I_{P_{1}}$ and $c_{P_{1}}$ are the intensity and the concentration of $P_{1}$ ion, and $\beta$ is the proportionality constant.

Substituting Eqn. 2 into Eqn. 7 with rearrangements results in the dependence of signal intensity of $P_{l}$ on the laboratory frame collision energy as given by

$$
I_{P_{1}}=\frac{k_{1}^{j} \tau \beta c_{A, o}}{k_{1}^{j} \tau-\Sigma k_{i} \tau}\left[\exp \left(-\Sigma k_{i} \tau\right)-\exp \left(-k_{1}^{j} \tau\right)\right]
$$

Using parameters $a_{1}, a_{2}, a_{3}, b_{1}$, and $b_{2}$ for the following expressions, $k_{1} \tau=a_{1} \exp \left(-b_{1} / E_{c}\right)$, $\Sigma k_{i} \tau=a_{2} \exp \left(-b_{2} / E_{c}\right)$, and $\beta c_{A, o}=a_{3}$, and by substitution of these expressions into Eqn. 8 , the theoretical dependence of the signal intensity on the lab frame collision energy can be simulated to fit the experimental intensities. For the sake of simplicity, we assume a single exponential expression for $\Sigma k_{i} \tau$. Figure 7 shows the dependencies of the signal intensities on the lab frame collision energy $\left(\mathrm{E}_{\mathrm{c}}\right)$ for the product ion $[\mathrm{P}+2 \mathrm{Na}]^{2+}$ formed from the precursor ions $\left[\mathrm{P} \_\mathrm{Cf}+2 \mathrm{Na}\right]^{2+}$ and $\left[\mathrm{P} \_\mathrm{Cf}+3 \mathrm{Na}\right]^{3+}$, together with the curves calculated by Eqn. 8 . The values of $\mathrm{E}_{\mathrm{c}}$ versus the intensities of $[\mathrm{P}+2 \mathrm{Na}]^{2+}$ ions are listed in Table 1 .

Fig. 7.

Table 1.

As it turns out from Fig. 7, the experimental intensities for the product ions can be described using the kinetic approximations depicted above. Moreover, a more precise description of the processes occurring in a mass spectrometer is also possible by means of a highly sophisticated computer program based on the Rice-Ramsperger-Kassel-Marcus (RRKM) theory [14]. 


\section{Conclusion}

The fragmentation behaviors of adducts of the ciprofloxacin- poly(ethylene glycol) conjugate with alkali metal ions $\left(\mathrm{Li}^{+}, \mathrm{Na}^{+}, \mathrm{K}^{+}\right)$were studied by tandem mass spectrometry. It was found that the metal cation does not significantly affect the fragmentation properties of singly, doubly, or triply charged adducts of the ciprofloxacin-poly(ethylene glycol) conjugate. Similar survival yield curves were recorded, independently of the cation, for the singly and doubly charged adducts. However, for the triply charged ions, breakdown curves shifted to higher collision energies in the order $\mathrm{K}^{+}<\mathrm{Na}^{+}<\mathrm{Li}^{+}$. Thus, the effect of charge repulsion between the cations upon the dissociation of adducts becomes more pronounced for triply charged adduct ions. Based on the experimental results, a general fragmentation scheme was proposed for the singly and multiply charged adducts of the ciprofloxacin-poly(ethylene glycol) conjugate with alkali metal ions. For the description of the variation of the product ion intensity with the laboratory frame collision energy, a simple model including the Arrheniustype equation for the unimolecular rate constants was also proposed.

\section{Acknowledgments}

This work was financially supported by the grants Nos. K-62213 and K-72524 given by OTKA (National Scientific Research Fund, Hungary) and the grants RET-006/2004 and GVOP-3.2.1.-2004-04-0152/3.0. 


\section{References}

1.

2.

3.

4.

5.

6.

7.

8. H. Giamarellou, A. Efstratiou, J. Tsagarakis, G. Petrikkos, G. Daikos, ArzneimittelForschung 34 (1984) 1775.

9. M.N. Swartz, N. Engl, J. Med. 345 (2001) 1621.

10. Counsil regulation (EEC) 2377/90: http://eur-lex.europa.eu/LexUriServ/ LexUriServ.do?uri=CONSLEG:1990R2377:20070121:EN:PDF

11. A. Rubies, R. Vaquerizo, F. Centrich, R. Compano, M. Granados, M.D. Prat, Talanta, 72 (2007) 269.

12. M.J. Schneider, L. Vázquez-Moreno, M.C. Bermúdez-Almada, R. Barraza, M. OrtegaNieblas, J. AOAC Int. 88 (2005) 1160.

13. N. Van Hoof, K. De Wasch, L. Okerman, W. Reybroek, S. Poelmans, H. Noppe, H. De Brabander, Anal. Chim. Acta, 529 (2005) 265.

14. M.P. Hermo, D. Barrón, J. Barbosa, J. Chromatogr. A. 1104 (2006) 132.

15. K. Granelli, C. Branzell, Anal. Chim. Acta, 586 (2007) 289.

16. H.B. Lee, T.E. Peart, M.L. Svoboda, J. Chromat. A. 1139 (2007) 45.

17. O. Ballesteros, V. Sanz-Nebot, A. Navalón, J.L. Vílchez, J. Barbosa, Chromatographia, 59 (2004) 543.

18. D.A. Volmer, B. Mansoori, S.J. Locke, Anal. Chem. 69 (1997) 4143.

19. P.A. Dagostino, J.R. Hancock, L.R. Provost, Rapid Commun. Mass Spectrom. 9 (1995) 1038.

20. B. Schneider, D.D.Y. Chen, Anal. Chem. 72 (2000) 791.

21. L. Drahos, K. Vékey, J. Mass Spectrom. 36 (2001) 237. 


\title{
Legends for the Schemes and Figures
}

\author{
Scheme 1. \\ Structure of the ciprofloxacin-poly(ethylene glycol) conjugate ( $\left.\mathrm{P}_{-} \mathrm{Cf}\right)$
}

\section{Scheme 2.}

Proposed fragmentation pathway for the ciprofloxacin-poly(ethylene glycol) conjugate (P_Cf) cationized with alkali metal ions $(\mathrm{M}=\mathrm{Li}, \mathrm{Na}, \mathrm{K}$ and $\mathrm{x}=2,3)$.

\section{Scheme 3.}

Simplified reaction scheme derived from Scheme 2 for the first-order, parallel, consecutive reactions.

\section{Fig.1.}

Electrospray mass spectrum of ciprofloxacin-poly(ethylene glycol) conjugate obtained in the presence of sodium ions.

\section{Fig. 2.}

Dependence of the degree of polymerization of the most intensive peak position on the alkali metal ions and the charge.

Fig. 3.

First-generation product ion spectrum of the doubly charged ciprofloxacin-poly(ethylene glycol) conjugate with sodium ions obtained at collision energy $53 \mathrm{eV}$ (in the lab frame).

(Precursor ions contain $n=22$ repeat units, i.e., ethylene oxide units.)

\section{Fig. 4.}

Breakdown curves for the doubly charged ciprofloxacin-poly(ethylene glycol) conjugate with sodium ions.

Fig. 5.

Breakdown curves for the triply charged ciprofloxacin-poly(ethylene glycol) conjugate with sodium ions.

Fig. 6.

Breakdown curves for the singly and multiply charged ciprofloxacin-poly(ethylene glycol) conjugate with different alkali metal ions.

Fig. 7.

Variation of the signal intensities with the lab frame collision energy $\left(\mathrm{E}_{\mathrm{c}}\right)$ for the product ion $[\mathrm{P}+2 \mathrm{Na}]^{2+}$ formed from the precursor ions $\left[\mathrm{P} \_\mathrm{Cf}+2 \mathrm{Na}\right]^{2+}$ and $\left[\mathrm{P} \_\mathrm{Cf}+3 \mathrm{Na}\right]^{3+}$. The solid lines represent the values calculated using Eqn. 4. Parameters used for $\left[\mathrm{P} \_\mathrm{Cf}+2 \mathrm{Na}\right]^{2+}$ are $a_{l}=1040$, $a_{2}=100, a_{3}=17700, b_{1}=400$, and $b_{2}=395$; those for $\left[\mathrm{P} \_\mathrm{Cf}+3 \mathrm{Na}\right]^{3+}$ are $\bar{a}_{1}=470, a_{2}=590, a_{3}=2500$, $b_{1}=240$, and $b_{2}=260$. 
Table 1. Lab frame collision energy $\left(\mathrm{E}_{\mathrm{c}}\right)$ versus signal intensities values for the product ion $[\mathrm{P}+2 \mathrm{Na}]^{2+}$ formed from the precursor ions $\left[\mathrm{P} \_\mathrm{Cf}+2 \mathrm{Na}\right]^{2+}$ and $\left[\mathrm{P} \_\mathrm{Cf}+3 \mathrm{Na}\right]^{3+}$.

\begin{tabular}{|c|c|c|c|c|c|c|c|c|c|c|c|c|}
\hline & \multicolumn{12}{|c|}{$[\mathrm{P} C \mathrm{Cf}+2 \mathrm{Na}]^{2+}$} \\
\hline $\mathrm{E}_{\mathrm{c}} / \mathrm{eV}$ & 30 & 35 & 38 & 40 & 43 & 45 & 48 & 50 & 53 & 55 & 60 & 65 \\
\hline Intensity & 49 & 202 & 478 & 808 & 1533 & 2186 & 3499 & 4338 & 5279 & 6483 & 5911 & 4216 \\
\hline & \multicolumn{12}{|c|}{$\left[\begin{array}{ll}\mathrm{P} & \mathrm{Cf}+3 \mathrm{Na}\end{array}\right]^{3+}$} \\
\hline $\mathrm{E}_{\mathrm{c}} / \mathrm{eV}$ & 20 & 23 & 27 & 30 & 33 & 37 & 40 & 47 & 50 & 55 & & \\
\hline Intensity & 12 & 40 & 133 & 321 & 600 & 854 & 981 & 640 & 184 & 23 & & \\
\hline
\end{tabular}


Scheme 1.

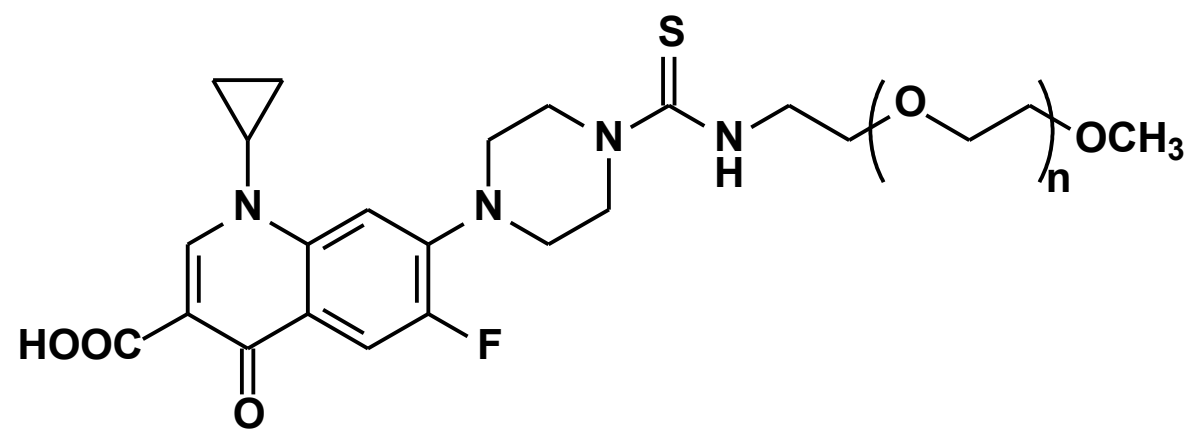


Scheme 2.

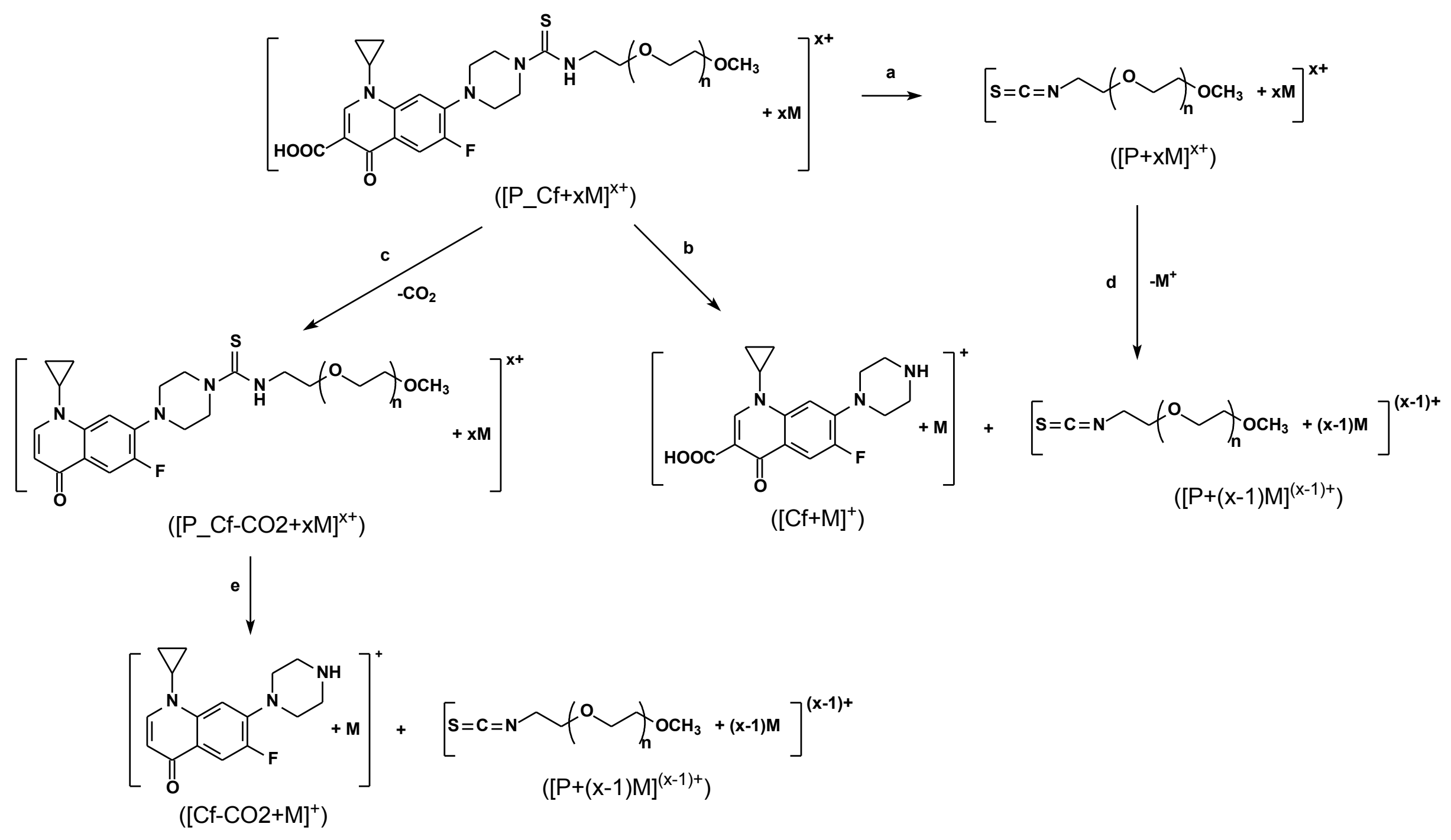


Scheme 3.

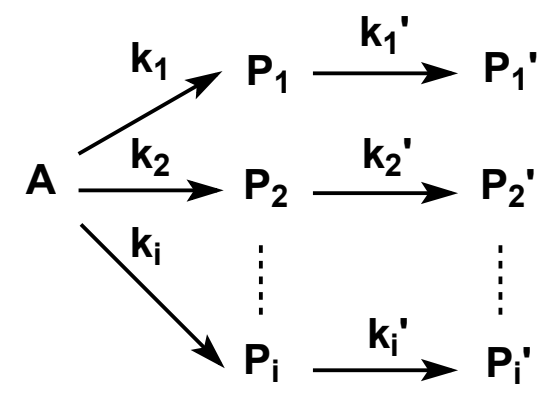


Fig. 1.

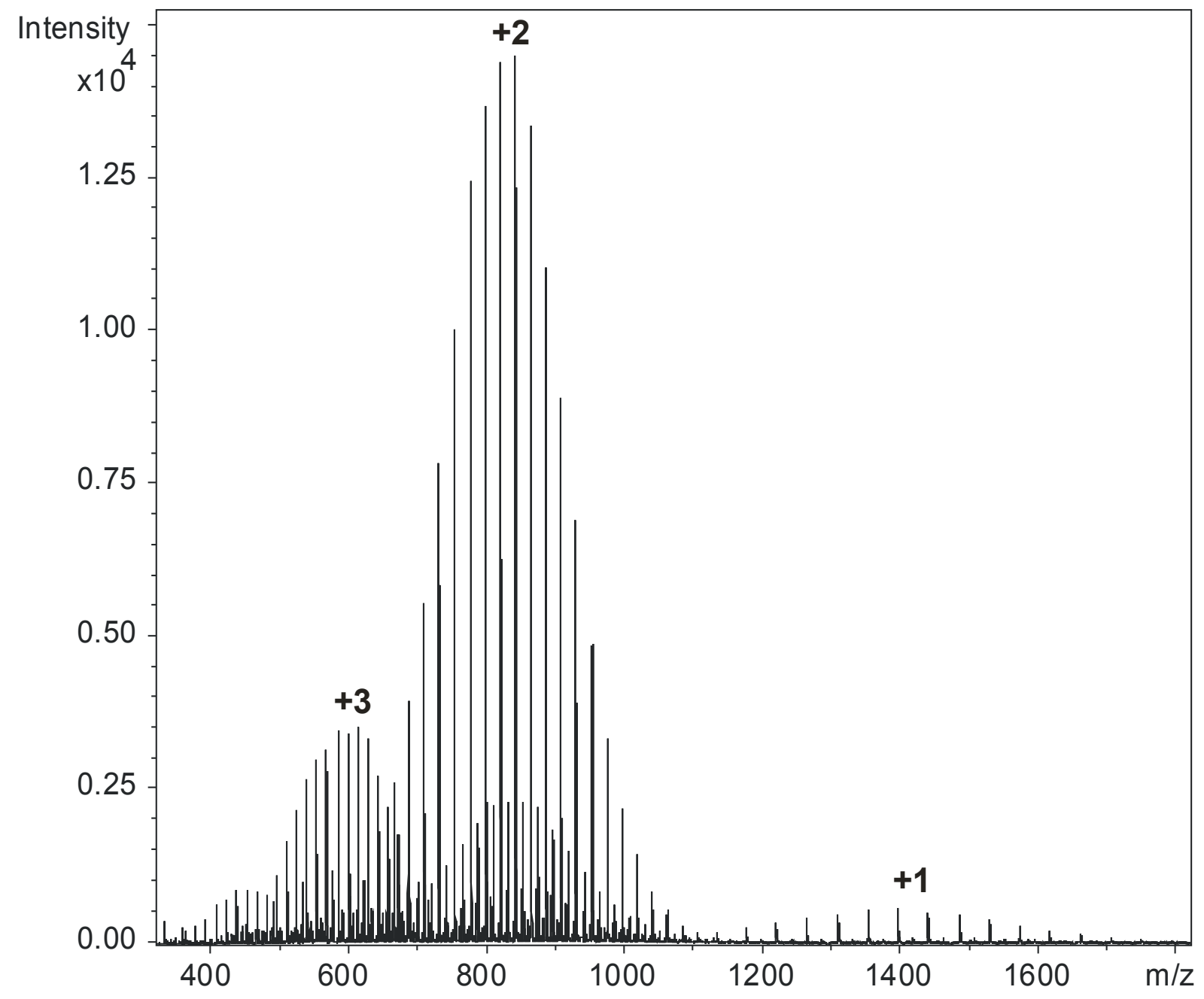


Fig. 2.

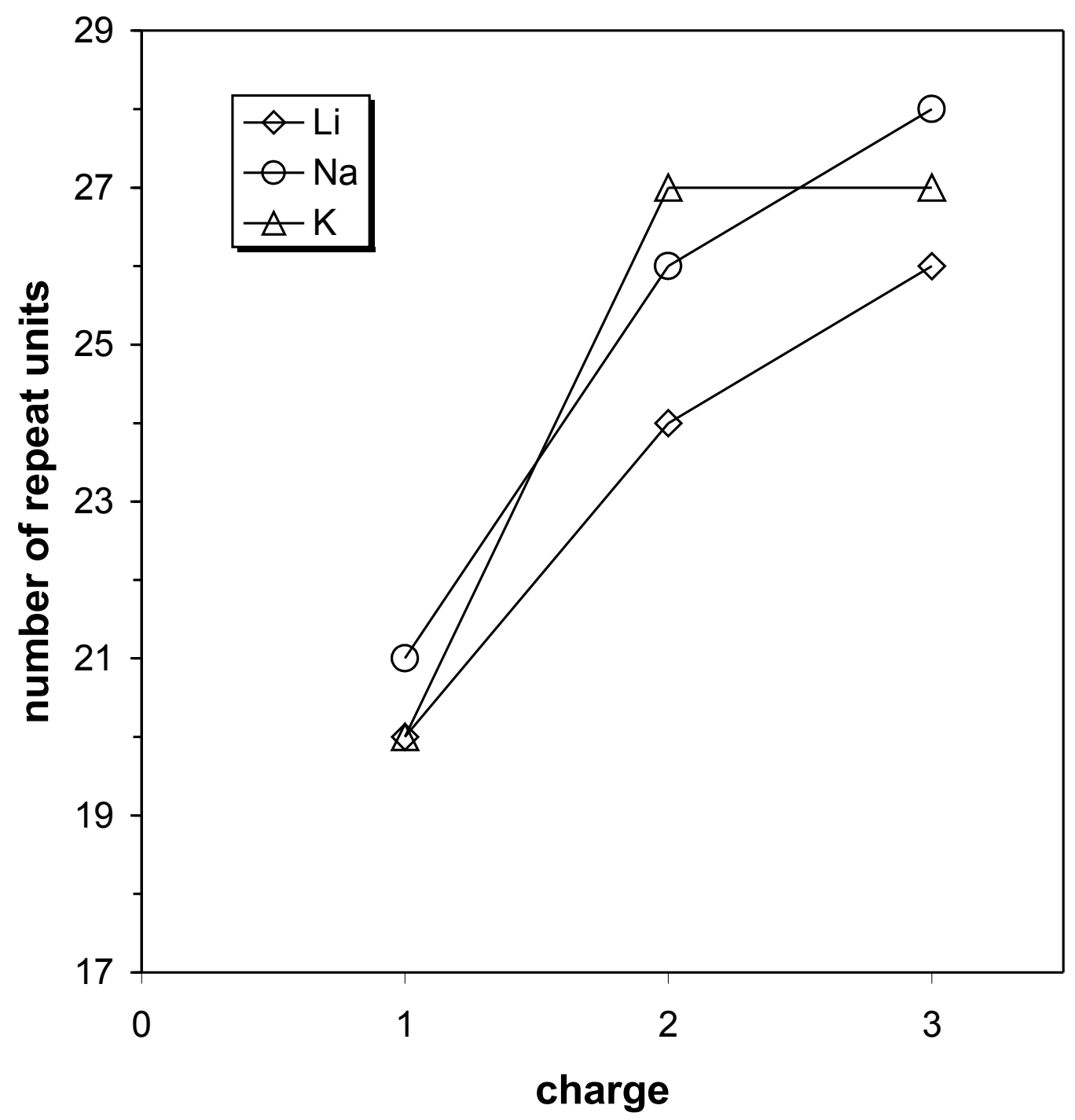


Fig. 3.

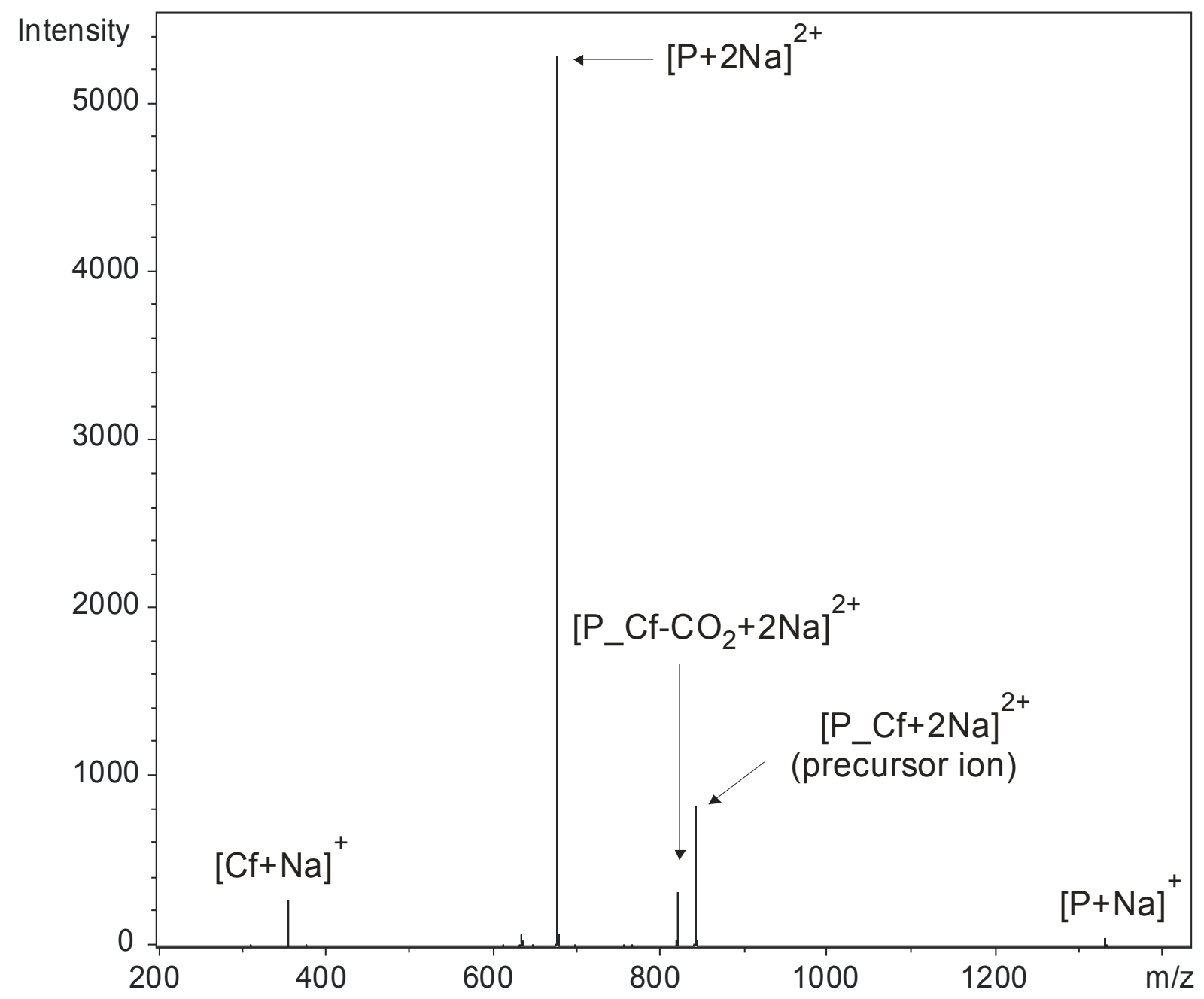


Fig. 4.

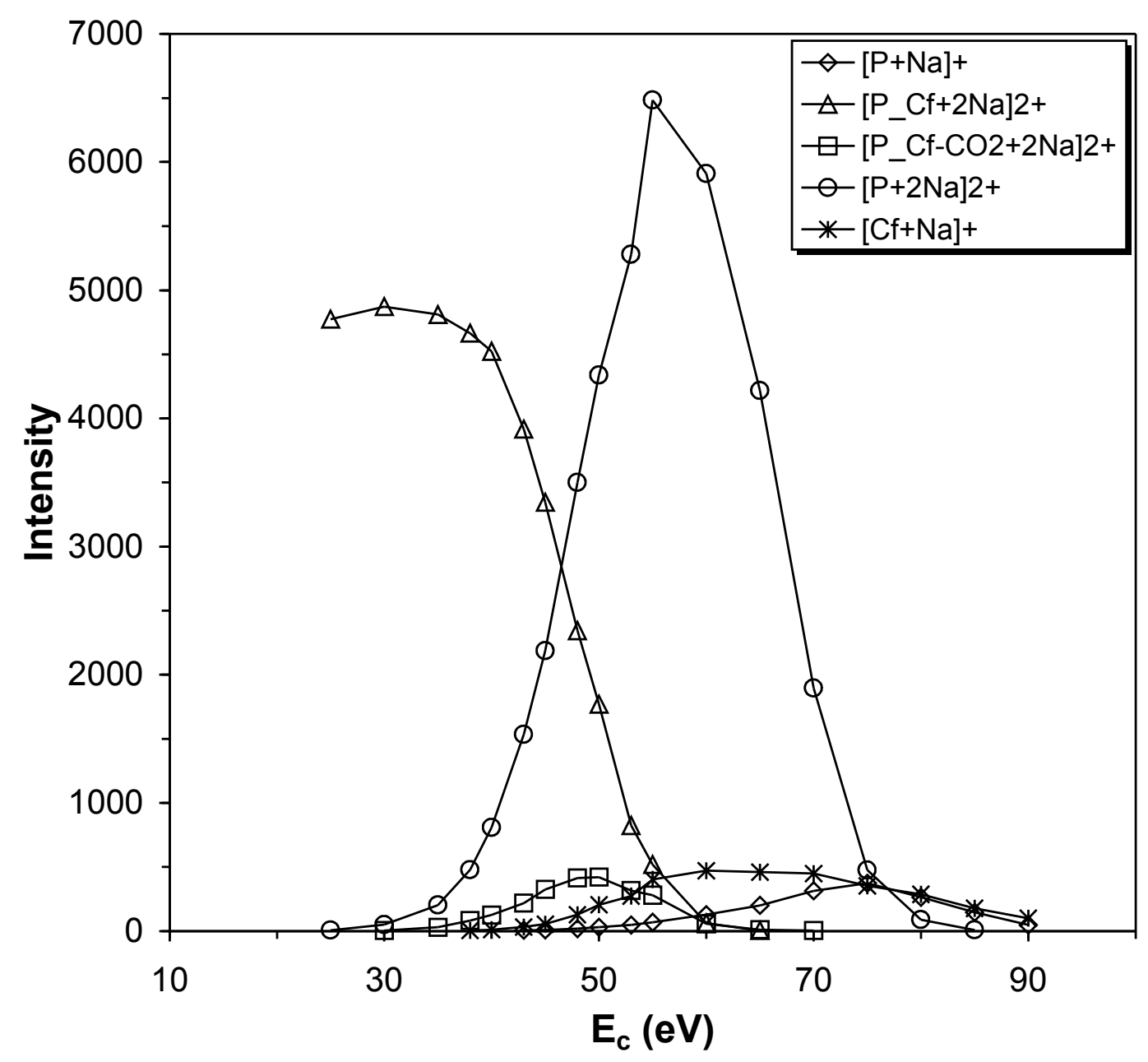


Fig. 5.

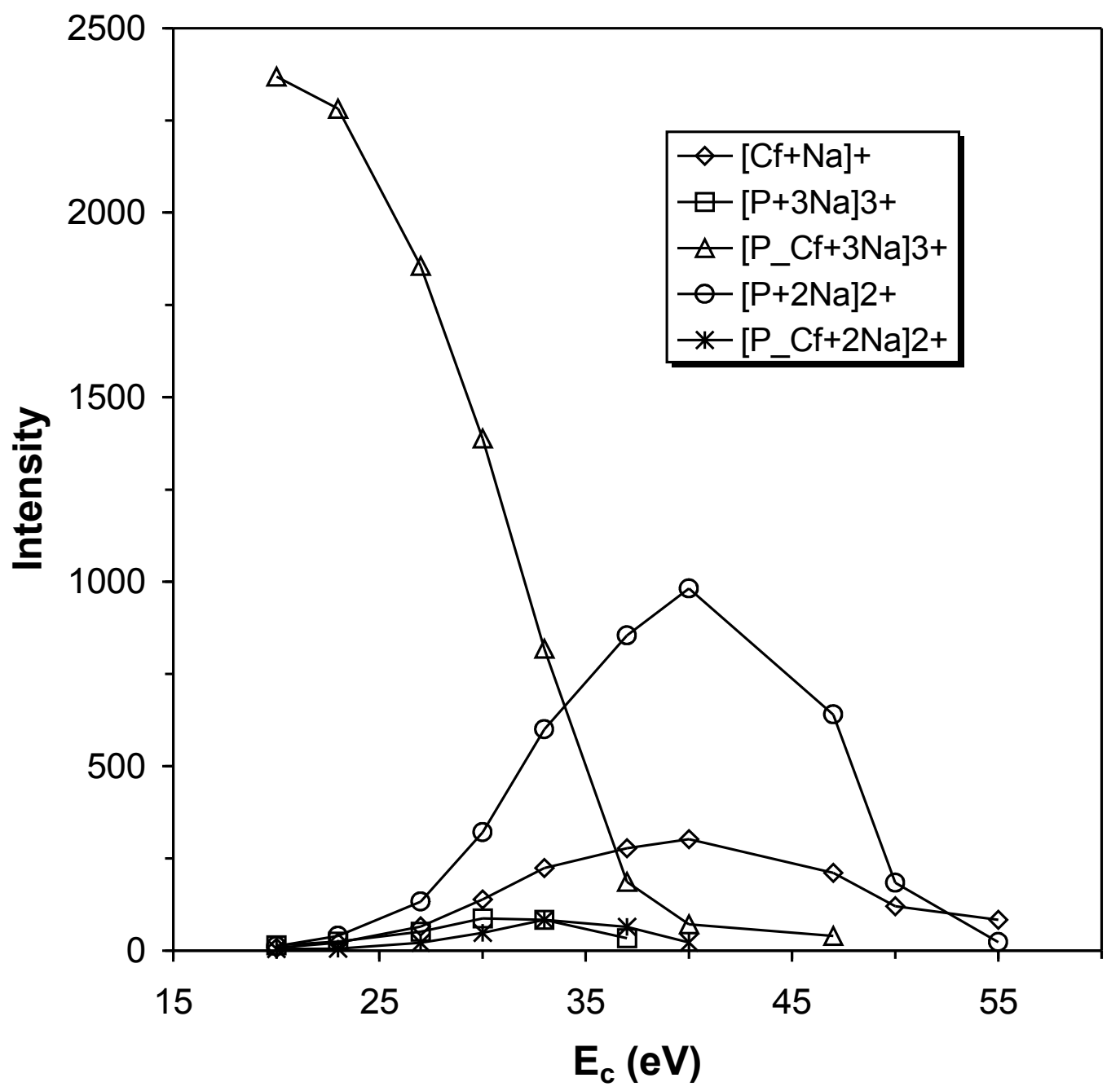


Fig. 6.

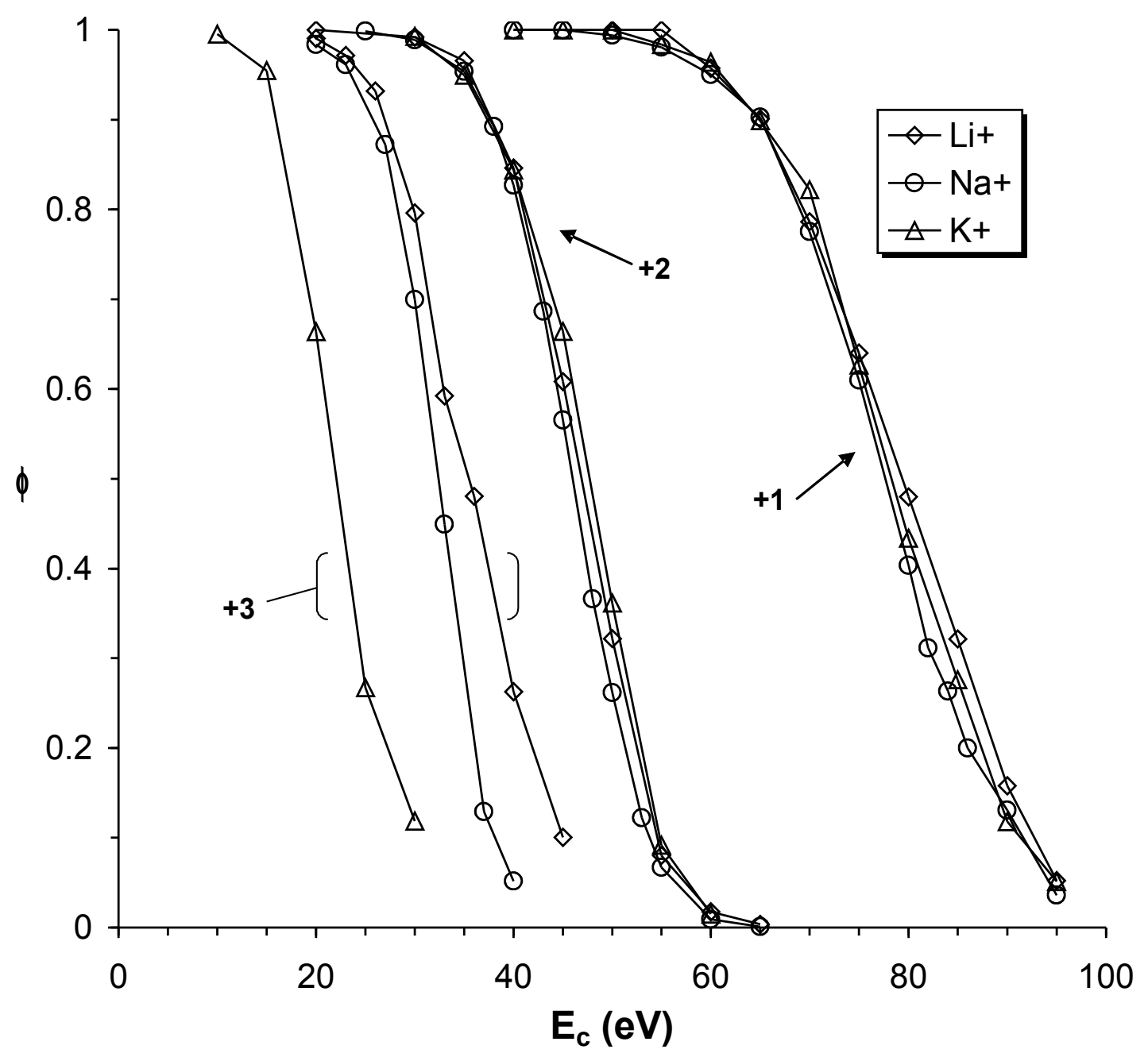


Fig. 7.

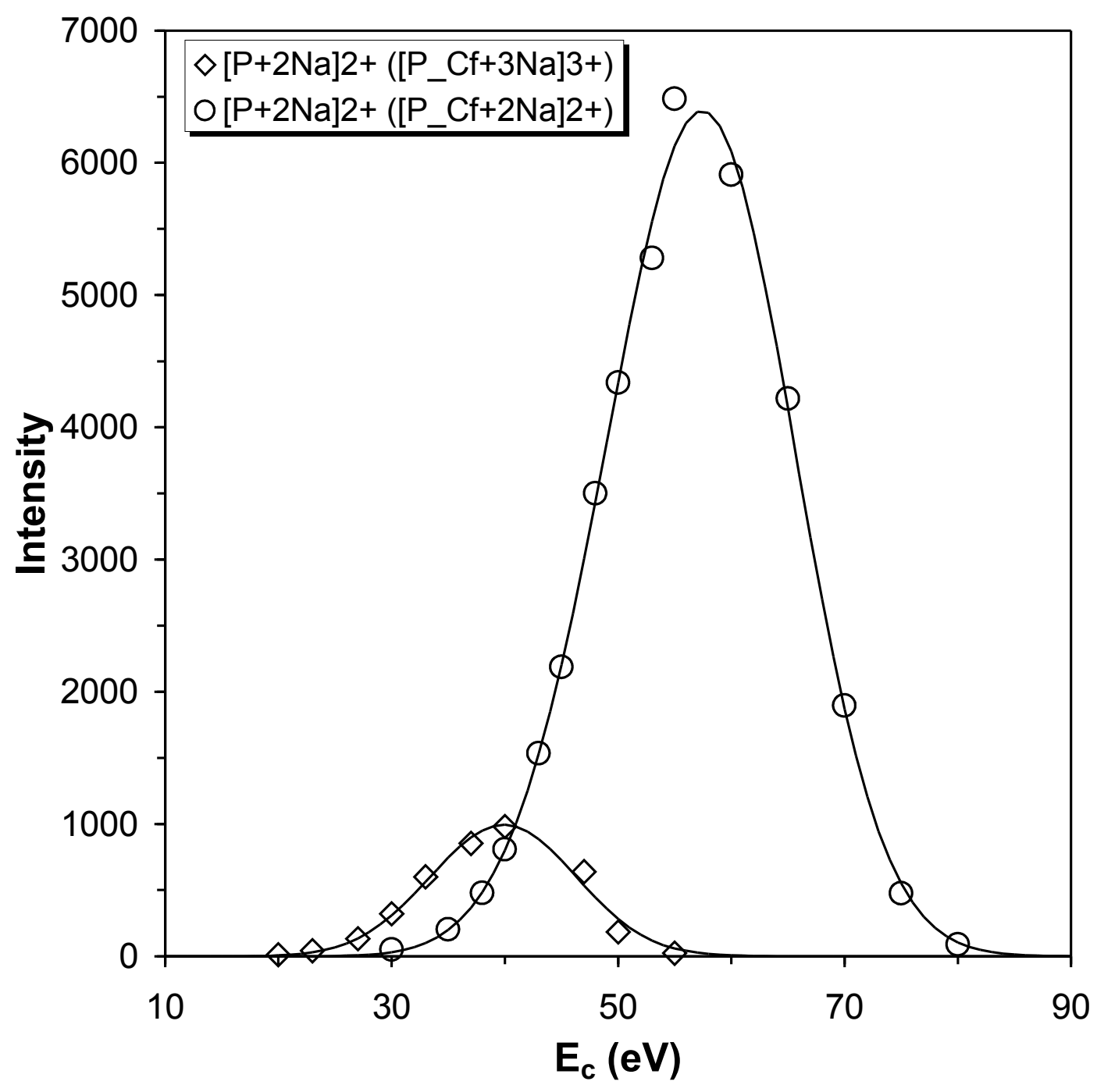

